\title{
INDEKS GLIKEMIK PANGAN DAN PENILAIAN STATUS GIZI PENDERITA DIABETES MELLITUS TIPE 2
}

\author{
FOOD GLICEMIC INDEX AND ASSESSMENT OF NUTRITIONAL STATUS IN \\ DIABETES MELLITUS TYPE 2 PATIENTS \\ Eliza $^{1}$, Imelda Telisa ${ }^{1}$, Manuntun Rotua ${ }^{1}$ \\ ${ }^{1}$ Jurusan Gizi Politeknik Kesehatan Kementerian Kesehatan Palembang, Sumatera Selatan Indonesia \\ (penulis korespodensi : eliza_limar@yahoo.co.id)
}

Latar Belakang: International Diabetes Federation (IDF) menyatakan bahwa lebih dari 382 juta orang di dunia penderita Diabetes mellitus. Indonesia merupakan negara yang menempati urutan ketujuh di dunia dengan jumlah penderita diabetes sebanyak 10 juta jiwa. Perencanaan makan yang tidak baik menyebabkan tidak adanya keseimbangan asupan zat gizi pada penderita Diabetes mellitus. Tujuan penelitian untuk mengetahui asupan indeks glikemik pangan, penilaian status gizi dan kadar glukosa darah pada penderita Diabetes Mellitus tipe 2 di Puskesmas Sosial Kota Palembang.

Metode: Penelitian ini adalah observasional analitik dengan rancangan potong lintang. Pengambilan sampel dilakukan secara purposive sampling sebanyak 80 orang. Data asupan makanan responden diperoleh dengan wawancara dengan metode food record 3 x 24 jam. Lingkar pinggang diukur menggunakan pita pengukur dengan ketelitian $0,1 \mathrm{~cm}$. Komposisi lemak tubuh diukur dengan menggunakan Body Index Analyzer (BIA). Pengukuran kadar glukosa darah dengan menggunakan alat digital glucometer.

Hasil: Hasil penelitian menunjukkan bahwa sebesar $60 \%$ kadar glukosa darah pasien adalah hiperglikemia. Ada hubungan yang signifikan antara asupan indeks glikemik pangan dengan kadar glukosa darah (nilai $p=0,018$ ). Ada hubungan yang signifikan antara lingkar pinggang dengan kadar glukosa darah (nilai $\mathrm{p}=0,0005$ ). Ada hubungan yang signifikan antara komposisi lemak tubuh dengan kadar glukosa darah ( $\mathrm{p}$ value $=0,021$ ).

Kesimpulan: Asupan indeks glikemik pangan yang tinggi, lingkar pinggang yang besar (obesitas) dan komposisi lemak tubuh yang obesitas akan menyebabkan kadar glukosa darah tinggi.

Kata Kunci : indeks glikemik pangan, lingkar pinggang, komposisi lemak tubuh, diabetes mellitus

\section{ABSTRACT}

Background: The International Diabetes Federation (IDF) stated that more than 382 million people in the world suffer from Diabetes mellitus. Indonesia was a country that ranks seventh in the world with 10 million people with diabetes. Poor eating planning causes an imbalance in nutrient intake in patients with Diabetes mellitus. The research purposed were to determine the intake of food glycemic index, assessment of nutritional status and blood glucose levels in type 2 Diabetes Mellitus patients in Palembang Social Health Center.

Method: This research was analytic observational with a cross sectional study design. Sampling was done by purposive sampling of 80 people. Respondent's food intake data obtained by interviews with the food record method $3 \times 24$ hours. Circle the exchange rate using a measuring tape with the accuracy of $0.1 \mathrm{~cm}$. Body fat composition was measured using a Body Index Analyzer (BIA). Measurement of blood glucose levels using a digital glucometer.

Results: The results showed that $60.0 \%$ of the patient's blood glucose test levels were hyperglycemia. There was a significant relationship between food glycemic index with blood glucose levels ( $p$ value $=$ 0,018 ), There was a significant relationship between waist circumference with blood glucose levels ( $p$ value $=0,000)$ and There was a significant relationship between body fat composition with blood glucose level ( $p$ value $=0,021$.)

Conclusion: There were significant relationship between the intake of food glycemic index, waist circumference and body fat composition with calcium levels in Diabetes Mellitus patients in Palembang Social Health Center.

Keywords: food glycemic index, waist circumference, body fat composition, diabetes mellitus 


\section{PENDAHULUAN}

Diabetes mellitus (DM) merupakan masalah kesehatan yang besar didunia. Diabetes mellitus menduduki peringkat ke-2 di dunia dibandingkan penyakit lain. Lebih dari 382 juta orang di dunia penderita Diabetes Mellitus ${ }^{1}$. International Diabetes Federation (IDF) menyatakan bahwa lebih dari 382 juta orang di dunia penderita Diabetes mellitus. Indonesia merupakan negara yang menempati urutan ketujuh di dunia dengan jumlah penderita diabetes sebanyak 10 juta jiwa. ${ }^{2}$ Prevalensi Diabetes Mellitus di Indonesia berdasarkan pemeriksaan darah pada penduduk umur $\geq 15$ tahun pada tahun 2018 mengalami peningkatan yaitu sebesar 8,5 $\%$ dibandingkan pada tahun $2013(6,9 \%){ }^{3}$ Prevalensi Diabetes Mellitus pada kelompok umur $>15$ tahun di Sumatera Selatan mengalami kenaikkan sebesar $0,4 \%$, dari $0,9 \%$ pada tahun 2013 menjadi $1,3 \%$ pada tahun 2018 .

Perencanaan makan yang tidak baik menyebabkan tidak adanya keseimbangan asupan zat gizi pada penderita Diabetes mellitus. Makanan yang mengandung indeks glikemik yang tinggi dapat meningkatkan resistensi insulin dan penurunan kerja pangkreas karena memproduksi insulin lebih banyak. ${ }^{5}$ Konsumsi makanan yang mengandung indeks glikemik

\section{METODE}

Penelitian ini merupakan penelitian observasional analitik menggunakan desain cross sectional. Penelitian dilakukan di Puskesmas Sosial Kota Palembang Provinsi Sumatera Selatan pada bulan Oktober sampai November Tahun 2018. Jumlah sampel sebanyak 80 orang.

Pengambilan sampel penelitian dilakukan secara purposive sampling. Kriteria inklusi dalam penelitian adalah penderita Diabetes Melitus tipe II yang dirawat jalan di Puskesmas Sosial Kota Palembang, dalam keadaan sadar dan mampu berkomunikasi dengan baik dan bersedia menjadi responden.

Jenis data terdiri dari data primer dan data sekunder. Data primer terdiri dari identitas responden yang diperoleh melalui wawancara langsung kepada responden dengan form identitas, data asupan makanan diperoleh dengan
(IG) yang tinggi secara sering berhubungan positif terhadap peningkatan risiko kejadian DM. $^{6}$

Obesitas menyebabkan resistensi insulin yang dapat berdampak buruk terhadap jaringan sehingga menimbulkan komplikasi kronis terutama obesitas sentral karena lipolisis yang terjadi pada obesitas sentral lebih resisten terhadap efek insulin bila dibandingkan dengan jaringan adiposit di daerah lain. ${ }^{7}$ Adanya hubungan yang erat antara status gizi lebih dengan status glukosa darah. ${ }^{8}$

Mengingat prevalensi penyakit Diabetes mellitus di Indonesia masih sangat tinggi begitu pula prevalensi penyakit Diabetes mellitus untuk Provinsi Sumatera Selatan juga tinggi yaitu 1,3\% , maka peneliti tertarik untuk meneliti tentang indeks glikemik pangan, penilaian status gizi yaitu lingkar pinggang dan komposisi lemak tubuh) pada pasien Diabetes mellitus di Puskesmas Sosial Palembang. Tujuan penelitian ini adalah untuk mengetahui hubungan antara asupan indeks glikemik pangan, lingkar pinggang, komposisi lemak tubuh dengan kadar glukosa darah pada penderita Diabetes mellitus di Puskesmas Sosial Kota Palembang.

metode food record 3 x 24 jam. Data lingkar pinggang diukur menggunakan pita pengukur dengan ketelitian $0,1 \mathrm{~cm}$. Data komposisi lemak tubuh diukur dengan menggunakan Body Index Analyzer (BIA). Data kadar glukosa darah sewaktu diambil dengan cara mengambil darah kapiler dengan menggunakan alat digital glucometer. Data sekunder mengenai gambaran umum lokasi penelitian diperoleh melalui observasi

Menggunakan analisis univariat dan analisis bivariat. Analisis univariat untuk melihat gambaran distribuis masing-masing variabel. Uji statistik bivariat untuk melihat hubungan antara variable bebas dengan variabel terikat menggunakan adalah uji chi square. 


\section{HASIL}

Hasil analisis univariat terdiri dari distribusi karakteristik penderita dapat dilihat pada Tabel 1. Distribusi kadar glukosa darah, asupan indeks glikemik pangan, lingkar pinggang, komposisi lemak tubuh penderita dapat dilihat Tabel 2. Berdasarkan Tabel 1 terlihat bahwa sebagian besar penderita berjenis kelamin perempuan yaitu $62,5 \%$ dan pria $37,5 \%$. Dilhat dari pekerjaan, sebagian besar penderita adalah ibu rumah tangga yaitu 48,8\%. Pendidikan dikelompokkan menjadi tiga kategori yaitu pendidikan dasar (tidak sekolah, SD tidak tamat, SD dan SLTP), Pendidikan menengah (SLTA) dan pendidikan tinggi (Akademi/PT). Berdasarkan Pendidikan dapat dilihat bahwa sebagian besar penderita termasuk pada kategori berpendidikan menengah yaitu sebesar $53,7 \%$.

Tabel 1. Distribusi Karakteristik Penderita

\begin{tabular}{lcc}
\hline Karakteristik Penderita & Jumlah & Persentase (\%) \\
\hline Jenis kelamin & & \\
Laki-Laki & 30 & 37,5 \\
Perempuan & 50 & 62,5 \\
Pekerjaan & & \\
Pensiunan/Tidak Bekerja & 17 & 21,3 \\
PNS/TNI /Polri & 2 & 2,5 \\
Pedagang / Wiraswasta & 12 & 15,0 \\
Pegawai / Karyawan Swasta & 6 & 7,5 \\
Ibu Rumah Tangga & 39 & 48,8 \\
Buruh & 4 & 5,0 \\
Pendidikan & & $\%$ \\
Dasar & 29 & $36, .3$ \\
Menengah & 43 & 53,7 \\
Tinggi & 8 & 10,0 \\
\hline
\end{tabular}

Kadar glukosa darah responden yang diambil adalah glukosa darah sewaktu yang dikategorikan menjadi dua yaitu tinggi (hiperglikemia) dan normal. Berdasarkan tabel 2 dapat dilihat bahwa sebagian besar kadar glukosa darah penderita di Puskesmas Sosial Palembang memiliki kadar glukosa darah dengan kategori hiperglikemia sebanyak 48 responden $(60,0 \%)$. Sebagian besar penderita mengonsumsi makanan yang memiliki indeks glikemik pangan tinggi yaitu sebanyak 69 responden $(86,2 \%)$. Status gizi penderita berdasarkan pengukuran lingkar pinggang sebagian besar dengan kategori obesitas yaitu sebanyak 46 responden $(57,5 \%)$. Status gizi penderita berdasarkan komposisi lemak tubuh sebagian besar dengan kategori normal yaitu sebanyak 42 responden $(52,5 \%)$.

Tabel 2. Distribusi Kadar Glukosa Darah, Asupan Indeks Glikemik Pangan, Lingkar Pinggang dan Komposisi Lemak Tubuh Penderita

\begin{tabular}{lcc}
\hline Variabel & Jumlah & Persentase (\%) \\
\hline Glukosa Darah Penderita & & \\
Hiperglikemia & 48 & 60,0 \\
$\quad$ Normal & 32 & 40,0 \\
Asupan Indeks Glikemik Pangan Penderita & 1 & 1,3 \\
Rendah & 10 & 12,5 \\
Sedang & 69 & 86,2 \\
Tinggi & & \\
\hline
\end{tabular}


Lingkar Pinggang Penderita

Obesitas 46

Normal

Normal

Komposisi Lemak Tubuh Penderita

$\begin{array}{lcr}\text { Kurus } & 3 & 3,7 \\ \text { Normal } & 42 & 52,5 \\ \text { Lebih } & 35 & 43,8\end{array}$

Hasil analisis bivariat mengenai hubungan antara asupan indeks glikemik pangan, lingkar pinggang dan komposisi lemak tubuh dengan kadar glukosa darah dapat dilihat pada Tabel 3.

Dari Tabel 3 dapat terlihat bahwa penderita dengan kadar glukosa darah yang tinggi (hiperglikemia) banyak terjadi pada penderita dengan asupan indeks glikemik pangan tinggi yaitu sebesar $65,2 \%$ dibandingkan dengan penderita dengan asupan indeks glikemik sedang (27,3\%). Hasil uji statistik dengan chi square menunjukkan ada hubungan yang signifikan antara asupan indeks glikemik pangan dengan kadar glukosa darah ( $\mathrm{p}$ $=0,018$ ).

Penderita dengan kadar glukosa darah yang tinggi (hiperglikemia) banyak terjadi pada penderita dengan lingkar pinggang yang obesitas yaitu sebesar $84,8 \%$ dibandingkan dengan penderita dengan lingkar pinggang yang normal (26,5\%). Hasil uji statistik dengan chi square menunjukkan ada hubungan yang signifikan antara lingkar pinggang dengan kadar glukosa darah $(\mathrm{p}=0,000)$.

Berdasarkan komposisi lemak tubuh terlihat bahwa penderita dengan kadar glukosa darah yang tinggi (hiperglikemia) banyak terjadi pada penderita dengan komposisi lemak tubuh yang obesitas yaitu sebesar $74,3 \%$ dibandingkan dengan penderita dengan komposisi lemak tubuh yang normal $(48,9 \%)$. Hasil uji statistic dengan chi square menunjukkan ada hubungan yang signifikan antara komposisi lemak tubuh dengan kadar glukosa darah $(\mathrm{p}=0,021)$.

Tabel 3. Hubungan antara Asupan Indeks Glikemik Pangan , Lingkar Pinggang dan Komposisi Lemak Tubuh dengan Kadar Glukosa Darah pada Pasien Diabetes Mellitus

\begin{tabular}{|c|c|c|c|c|c|c|c|c|}
\hline \multirow{3}{*}{ Variabel } & \multicolumn{4}{|c|}{ Glukosa Darah } & \multirow{2}{*}{\multicolumn{2}{|c|}{ Jumlah }} & \multirow{3}{*}{ p value } & \multirow{3}{*}{ OR } \\
\hline & \multicolumn{2}{|c|}{ Hiperglikemia } & \multicolumn{2}{|c|}{ Normal } & & & & \\
\hline & Jumlah & $\begin{array}{c}\text { Persentase } \\
(\%)\end{array}$ & Jumlah & $\begin{array}{c}\text { Persentase } \\
(\%)\end{array}$ & Jumlah & $\begin{array}{c}\text { Persentase } \\
(\%)\end{array}$ & & \\
\hline \multicolumn{9}{|c|}{ Asupan Indeks Glikemik Pangan } \\
\hline Tinggi & 45 & 65,2 & 24 & 34,8 & 69 & 100 & \multirow[t]{2}{*}{0,018} & \multirow[t]{2}{*}{5,000} \\
\hline Sedang & 3 & 27,3 & 8 & 72.7 & 11 & 100 & & \\
\hline \multicolumn{9}{|c|}{ Lingkar Pinggang } \\
\hline Obesitas & 39 & 84,8 & 7 & 15,2 & 46 & 100 & \multirow[t]{2}{*}{0,000} & \multirow[t]{2}{*}{15,476} \\
\hline Normal & 9 & 26,5 & 25 & 73,5 & 34 & 100 & & \\
\hline \multicolumn{9}{|c|}{ Komposisi Lemak Tubuh } \\
\hline Obesitas & 26 & 74,3 & 9 & 25,7 & 35 & 100 & \multirow[t]{2}{*}{0,021} & \multirow[t]{2}{*}{3,020} \\
\hline Normal & 22 & 48,9 & 23 & 51,1 & 45 & 100 & & \\
\hline
\end{tabular}

\section{PEMBAHASAN}

Berdasarkan Tabel 1 dapat dilihat bahwa sebagian besar penderita adalah perempuan. Perempuan lebih berisiko terkena penyakit Diabetes mellitus karena secara fisik perempuan memiliki peluang mengalami peningkatan berat badan yang lebih besar. ${ }^{10}$ Setelah dilakukan recall asupan makanan, penderita perempuan lebih banyak mengkonsumsi karbohidrat dan lemak sehingga 
terjadinya penumpukan lemak dalam tubuh dan memicu timbulnya obesitas.

Sebagian besar penderita termasuk dalam kategori berpendidikan menengah. Hasil dimaksud dengan diet Diabetes mellitus selama ini dianjurkan ahli selama mereka melakukan konsultasi di Puskesmas Sosial Palembang. Tingkat pendidikan memiliki pengaruh terhadap kejadian penyakit Diabetes Melitus Tipe II. Orang yang tingkat pendidikannya tinggi biasanya akan memiliki banyak pengetahuan tentang kesehatan, dengan adanya pengetahuan tersebut oarang akan memiliki kesadaran dalam menjaga kesehatannya. ${ }^{11}$

Berdasarkan Tabel 3 dapat dilihat bahwa nilai odd rasio (OR) asupan indeks glikemik dengan kadar glukosa darah penderita adalah 5,000 artinya penderita yang mengosumsi makanan berindeks glikemik pangan tinggi 5 kali lebih besar berisiko hiperglikemia. Makanan yang mengandung indeks glikemik yang tinggi dapat meningkatkan resistensi insulin dan penurunan kerja pangkreas karena memproduksi insulin lebih banyak. Makanan yang mengandung indeks glikemik pangan yang tinggi banyak terdapat pada makanan dan minuman yang manis karena banyak mengandung glukosa yang sangat tinggi. ${ }^{12}$

Pangan yang mengandung banyak karbohidrat seperti beras, kentang dan roti yang bisa dicerna dan diserap sangat cepat sehingga dapat meningkatkan kadar glukosa dalam darah. Karbohidrat yang terdapat dalam pangan yang dapat dipecah dengan cepat selama proses percernaan memiliki indeks glikemik tinggi. Sebaliknya jika karbohidrat dalam pangan yang dipecah secara lambat sehingga pelepasan glukosa ke dalam darah berjalan lambat memiliki indeks glikemik rendah. ${ }^{13}$

Konsumsi pangan yang mengandung indeks glikemik (IG) yang tinggi secara sering berhubungan positif terhadap peningkatan risiko kejadian Diabetes mellitus. ${ }^{14}$ Konsumsi makanan manis seperti coklat, biskuit, cake, dalam otot. ${ }^{20}$

\section{KESIMPULAN DAN SARAN}

Sebagian besar penderita mengalami hiperglikemia, indeks glikemik pangan dengan kadar glukosa darah pada penderita Diabetes mellitus Tipe 2 berhubungan asupan makanan, penelitian menunjukkan bahwa sebagian besar penderita dengan tingkat pendidikan menegah belum mengetahui tentang apa sebenarnya yang

gizi diantaranya permen dan minuman ringan dapat meningkatkan asupan energi dan akan berpengaruh terhadap kejadian metabolik sindrom dengan indikator peningkatan glukosa darah puasa, lingkar pinggang yang berlebih, kadar kolesterol HDL yang rendah, serta peningkatan kolesterol LDL dan trigliserida. ${ }^{15}$

Nilai odd rasio (OR) lingkar pinggang dengan kadar glukosa darah yaitu 15,476 artinya penderita dengan lingkar pinggang yang obesitas 15,476 kali lebih besar berisiko hiperglikemia dibandingkan dengan lingkar pinggang yang normal. Lingkar pinggang yang berlebih berpengaruh terhadap kejadian DM tipe 2. Pria dengan lingkar pinggang lebih dari $90 \mathrm{~cm}$ dan wanita dengan lingkar pinggang lebih dari $80 \mathrm{~cm}$ memiliki risiko terhadap kejadian DM. ${ }^{16}$ Obesitas sentral sangat berpengaruh terhadap kadar glukosa darah. Oleh karena itu, pada orang dewasa harus mempertahankan status gizi normal agar tidak terjadi obesitas. ${ }^{17}$

Obesitas sangat erat hubungannya dengan Diabetes mellitus Tipe 2. Pada orang yang obesitas, terdapat kelebihan energi akibat makan makanan yang berlebih sehingga menimbulkan penimbunan lemak di jaringan kulit dan akan menyebabkan resistensi insulin. Resistensi insulin akan timbul pada daerah yang mengalami penimbunan lemak sehingga menghambat kerja insulin di jaringan tubuh dan otot. Hal tersebut akan menyebabkan glukosa tidak dapat diangkat ke dalam sel sehingga menyebabkan peningkatan kadar glukosa dalam darah. ${ }^{19}$ Timbunan lemak yang tinggi akan menyebabkan meningkatnya uptake sel terhadap asam lemak bebas dan akan memacu oksidasi lemak sehingga akan menghambat penggunaan glukosa

status gizi berdasarkan lingkar pinggang. Status gizi berdasarkan komposisi lemak tubuh juga berhubungan dengan kadar glukosa darah pada pasien Diabetes mellitus Tipe 2. Asupan indeks 
glikemik pangan yang tinggi, lingkar pinggang yang besar (obesitas) dan komposisi lemak tubuh yang obesitas akan menyebabkan kadar glukosa darah tinggi.

Gaya hidup merupakan hal yang penting dalam mengontrol kadar glukosa darah pada pasien DM. Pasien diharapkan dapat

\section{UCAPAN TERIMA KASIH}

Penulis mengucapkan terima kasih kepada Direktur Poltekkes Kemenkes Palembang yang sudah memfasilitasi dana penelitian, Dinas Kesehatan Kota Palembang,

\section{DAFTAR PUSTAKA}

1. International Diabetes Federation (IDF). 2013. IDF Diabetes Atlas Sixth Edition. http://www.idf.org/diabetes-evidencedemands-realaction-unsummit-noncommunicable-disease. Diakses tanggal 12 Januari 2018.

2. World Health Organization. 2011. Definition and Diagnosis of Diabetes Mellitus and HbA1C to Diagnostic. Diabetes Atlas. http://www.who.int/diabetes/en/ . Diakses pada tanggal 10 Oktober 2019).

3. Kementerian Kesehatan. 2018. Riset Kesehatan Dasar 2018. Jakarta (ID). Badan Penelitian dan Pengembangan Kementerian Kesehatan Republik Indonesia.

4. Kementerian Kesehatan. 2018. Riset Kesehatan Dasar 2018. Jakarta (ID). Badan Penelitian dan Pengembangan Kementerian Kesehatan Republik Indonesia.

5. Willett W, Manson J, Liu S. 2002. Glycemic index, glycemic load, and risk of type 2 diabetes. Am J Clin Nutr.76 (suppl):274S-80S.

6. Oba S, Nanri A, Kurotani K, Goto A, Kato M, Mizoue T, Noda M, Inoue M, Tsugane S. 2013. Dietary glycemic index, glycemic load and incidence of type 2 diabetes in Japanese men and women: the Japan public health center-based prospective study. Nutrition Journal.12(165) : 1 - 10.

7. Pusparini. 2007. Obesitas Sentral, Sindroma Metabolik dan Diabetes Mellitus Tipe menerapkan gaya hidup sehat seperti mengonsumsi makanan yang tinggi serat yang banyak terdapat dalam sayur dan buah, mengurangi mengonsumsi makanan/ minuman yang mengandung indeks glikemiks yang tinggi serta banyak melakukan aktivitas fisik supaya dapat menurunkan berat badan.

Pimpinan Puskesmas Sosial Palembang dan staf serta pihak-pihak yang telah membantu pelaksanaan penelitian ini.

File://C:/Users/user/Downloads/312-6301-SM\%20(4).pdf.

8. Zhang L, Shen Y, Zhou J, Pan Jm, Yu Hy, Chen Hb, Li Q, Li M, Bao Yq, Jia Wp. 2014. Relationship between waist circumference and elevation of carotid intima-media thickness in newlydiagnosed diabetic patients. Biomed Environ Sci. 27(5): 335-342. doi: 10.3967/bes2014.058.

9. Irawan D. 2010. Prevalensi dan Faktor Risiko Kejadian Diabetes Melitus Tipe 2 di Daerah Urban Indonesia (Analisa Data Sekunder Riskesdas 2007). Thesis Universitas Indonesia.

10. Irawan D. 2010. Prevalensi dan Faktor Risiko Kejadian Diabetes Melitus Tipe 2 di Daerah Urban Indonesia (Analisa Data Sekunder Riskesdas 2007). Thesis Universitas Indonesia.

11. Willett W, Manson J, Liu S. 2002. Glycemic index, glycemic load, and risk of type 2 diabetes. Am $J$ Clin Nutr.76(suppl):274S-80S.

12. Rimbawan dan Siagian. 2004. Indeks Glikemik Pangan. Bogor : Penebar Swadaya.

13. Oba S, Nanri A, Kurotani K, Goto A, Kato M, Mizoue T, Noda M, Inoue M, Tsugane S. 2013. Dietary glycemic index, glycemic load and incidence of type 2 diabetes in Japanese men and women: the Japan public health center-based prospective study. Nutrition Journal.12(165) : 1 - 10.

14. Mirmiran P, Bahadoran Z, Delshad H, Azizi F. 2014. Effects of energy-dense 
nutrient-poor snacks on the incidence of metabolic syndrome: A prospective approach in Tehran Lipid and Glucose Study. Nutrition. 30 : 538-543. doi: 10.1016/j.nut.2013.09.014.

15. Meisinger C, Döring A, Thorand B, Heier M, Löwel H. 2006. Body fat distribution and risk of type 2 diabetes in the general population: are there differences between men and women? The MONICA/KORA Augsburg Cohort Study. Am J Clin Nutr.84:483-489.

16. Zhang L, Shen Y, Zhou J, Pan Jm, Yu Hy, Chen $\mathrm{Hb}$, Li Q, Li M, Bao Yq, Jia Wp. 2014. Relationship between waist circumference and elevation of carotid intima-media thickness in newlydiagnosed diabetic patients. Biomed Environ Sci. 27(5): 335-342. doi: 10.3967/bes2014.058.

17. Soniya I, Devi MA, Rosemary S. 2014. Body composition in diabetes mellitus. IOSR Journal of Dental and Medical Sciences (IOSR-JDMS). 13(1-10): 68-70.

18. International Diabetes Federation. 2011. Diabetes Evidence Demands Real Action From The Un Summit On NonCommunicable Diseases. [http://www.idf.org/diabetes-evidencedemands-real-action-un-summit-noncommunicable-diseases].

19. Adnan M, Mulyati T, Isworo JT. 2013. Hubungan Indeks massa tubuh (IMT) dengan kadar gula darah penderita diabetes melitus (DM) tipe 2 rawat jalan di RS tugurejo semarang. Jurnal Gizi Muhammadiyah Semarang. 